\title{
Anthropometric Determinations of Umbilical Position in Iraqi Adults
}

\author{
Mazin Abdulsattar Abdulla ${ }^{1, \odot}$ Saja Mahmood Ali Fahad ${ }^{2}$ \\ ${ }^{1}$ Department of Surgery, College of Medicine, C.A.B.S. Basrah \\ Teaching Hospital, University of Basrah, Basrah, Iraq \\ 2Department of Human Anatomy and Histology, College of \\ Medicine, University of Basraha, Basrah, Iraq

\begin{abstract}
Address for correspondence Mazin Abdulsattar Abdulla, Department of Surgery, College of Medicine, C.A.B.S. Basrah Teaching Hospital, University of Basrah, Basrah, Ashar post, PO box 1035. Zip code, 61004, Iraq (e-mail: mazin.abdulla@uobasrah.edu.iq).
\end{abstract}

Indian J Plast Surg:2020;53:394-398

\begin{abstract}
Keywords

- umbilicus

- abdominoplasty

- measurements

Introduction Umbilicus is an important surface landmark on the anterior abdominal wall in addition to its aesthetic and psychological effect.

Objectives The objective of the study is to determine the position of umbilicus in Iraqi adults to provide a guide for the neoumbilicus in abdominoplasty.

Subjects and Methods This is an observational study performed on 100 volunteers with no abdominal wall abnormality. Measurements included weight, height, body mass index (BMI), distance from xiphoid to umbilicus, distance from xiphoid process to pubic symphysis, distance from xiphoid process to both anterior superior iliac spine (ASIS), distance from pubic symphysis to umbilicus and from pubic symphysis to xiphisternum, distance of umbilicus to both ASIS, and distance of umbilicus to interspinous line and to inter-anterior hypochondrium line.

Results The study included 100 volunteers, with $50 \%$ male and $50 \%$ female whose age ranges between 18 to 60 years. The results were a follows: distance from xiphoid process to umbilicus and distance from xiphoid process to pubic symphysis were $18.03 \pm$ $3.25 \mathrm{~cm}$ and $32.21 \pm 4.64 \mathrm{~cm}$, respectively; distances from xiphoid process to right ASIS and left ASIS were $25.95 \pm 5.72 \mathrm{~cm}$ and $25.84 \pm 6.02 \mathrm{~cm}$, respectively; distance from pubic symphysis to umbilicus was $17.66 \pm 3.12 \mathrm{~cm}$; distance of umbilicus to interspinous line was $9.25 \pm 1.84 \mathrm{~cm}$. The distance from umbilicus to inter anterior hypochondrium line was $9.905 \pm 2.19 \mathrm{~cm}$.

Conclusion These measurements can determine the neoumbilicus position, reduce practical mistakes, and improve postsurgical outcomes.
\end{abstract}

\section{Introduction}

Umbilicus stands as the bottleneck of the abdomen that transmits umbilical vessels and related structures of the urinary and digestive systems. A few days after birth, the umbilical stump falls and the scar remains. ${ }^{1}$ This umbilicus lies at the midline in linea alba. ${ }^{2,3}$ Umbilicus presents centrally in the midpoint of anterior abdominal wall, but this is an inconstant position, as it may be at a higher or lower position in a small proportion of population, ${ }^{4,5}$ or even not at the midline, ${ }^{6}$ but typically it lies at the high point level of iliac crest, opposite to the disc between third and fourth lumber vertebrae, ${ }^{7}$ or fourth lumber vertebra, ${ }^{8}$ or its lies matching one of tendinous transverse intersection of rectus abdominis muscle $^{9}$ published online

December 26, 2020
Dol https://doi.org/

10.1055/s-0040-1721869

ISSN 0970-0358.
(C)2020. Association of Plastic Surgeons of India.

This is an open access article published by Thieme under the terms of the Creative Commons Attribution-NonDerivative-NonCommercial-License, permitting copying and reproduction so long as the original work is given appropriate credit. Contents may not be used for commercial purposes, or adapted, remixed, transformed or built upon. (https://creativecommons.org/licenses/by-nc-nd/4.0/). Thieme Medical and Scientific Publishers Pvt. Ltd. A-12, 2nd Floor, Sector 2, Noida-201301 UP, India 
The umbilicus may be excised in surgical procedures as in some cases of umbilical herniorraphies, or surgical removal due to skin cancer, ${ }^{10,11}$ or it can be destroyed in serious burn of anterior abdominal wall or due to different wounds. ${ }^{12}$

Due to the appealing and inherent role of umbilicus in the abdomen, its removal may lead to some psychological disorder, and reconstruction of umbilicus becomes essential ${ }^{13}$

During abdominoplasty, which is a frequent operation for shaping the abdomen by removing excess fat and skin from anterior abdominal wall, ${ }^{14}$ the surgeon has to choose the expected position of umbilicus in order to locate it back. This needs anatomical analysis of umbilical position. ${ }^{14,15}$

Our main objective in this study is to define the position of umbilicus in Iraqi adult males and females through morphometric measurements, in order to help the surgeons delineate the position of neoumblicus in case a reconstructive procedure is attempted.

\section{Subjects and Methods}

This is an observational, cross-sectional study conducted to obtain the morphometric measurements of 100 adult (50 males and 50 females) volunteers. Their informed consent were taken after full explanation of the purpose of our study. Approval was obtained from the Scientific and Ethical committee in Basrah College of Medicine, while statistical analysis was performed using the MS Excel tool.

The morphometric measurements were taken for each person, according to a prepared data collection sheet.

The exclusion criteria were as follows: any abnormality, deformity or lesion of umbilicus, pregnancy or history of pregnancy, intra-abdominal masses, anterior abdominal wall pathologies, and history of abdominal surgery.

For each participant, the following data was gathered: age, height (in $\mathrm{cm}$ ), weight (in $\mathrm{kg}$ ), and BMI. All measurements were taken from bony prominence to the center of the umbilicus in centimeter and the instruments used were weight scale, measurement tape, thread, and skin marker. The measurements were taken in the supine position, because it is the position during surgery.

The volunteers were kept in supine position during measuring as shown in (-Fig. 1) and the dimensions recorded included the following: a-Distance from xiphoid process to umbilicus "Xu"; b-Distance from xiphoid process to pubic symphysis "Xp"; c-Interspinous line "inter ASIS"; d-Distance from umbilicus to pubic symphysis "Up"; e-Distance of umbilicus to ASIS "U-ASIS"; f-Distance of umbilicus to interspinous line "U-inter ASIS"; g-Distance of umbilicus to inter anterior hypochondrium line "U-i-hy"; h-Distance of xiphoid process to right ASIS "U-ASISr"; i-Distance of xiphoid process to left ASIS “U-ASISI”; j-Ratio between distance from xiphoid process to umbilicus and distance from umbilicus to pubic symphysis "Xu/Up"; k-Ratio between distance from xiphoid process to umbilicus and distance from xiphoid process to pubic symphysis "Xu/Xp"; 1-Ratio between distance from xiphoid process to pubic symphysis and distance from umbilicus to pubic symphysis "Xp/Up"; m-Ratio between distance from xiphoid process to pubic symphysis and Inter spinous line "Xp/inter ASIS"; n-Ratio between distance of umbilicus to ASIS and inter pinous line "U-ASIS/inter ASIS."

\section{Results}

The study included 100 volunteers, with 50 males (50\%) and 50 females (50\%) whose age ranged between 18 to 60 years (total mean age $29.32 \pm 12.26$ years); the other demographic data in addition to age pertained to weight, height and body mass index (BMI), and the mean values are presented in - Table 1. The umbilicus was located in the midline at xiphoid pubic line in all.

Measurements in relation to xiphoid process: distance from xiphoid process to umbilicus and distance from xiphoid process to pubic symphysis are $18.03 \pm 3.246 \mathrm{~cm}$ and $32.21 \pm$ $4.636 \mathrm{~cm}$, respectively. Distances from xiphoid process to
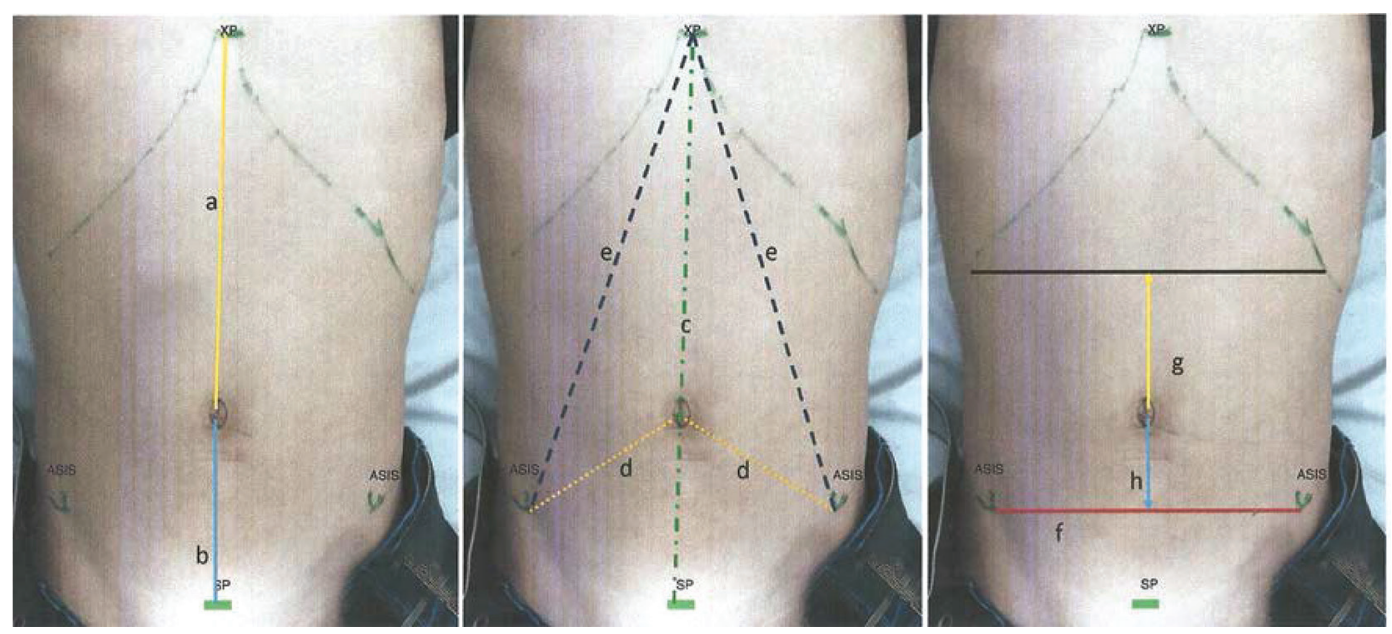

Fig. 1 Frontal view of the abdomen with a diagram of morphometric analysis of umbilicus: (a) distance from xiphoid process to umbilicus; (b) distance from umbilicus to pubic symphysis; (c) distance from xiphoid process to pubic symphysis; (d) distance of umbilicus to anterior superior iliac spine (ASIS); (e) distance of xiphoid process to ASIS interspinous line; (f) interspinous line; (g) distance of umbilicus to inter anterior hypochondrium line; (h) distance of umbilicus to interspinous line. 
Table 1 Demographic characteristics according to sex

\begin{tabular}{|c|c|c|c|c|c|c|}
\hline \multirow[t]{2}{*}{ Variables } & \multicolumn{2}{|c|}{$\begin{array}{l}\text { Female } \\
(N=50)\end{array}$} & \multicolumn{2}{|c|}{$\begin{array}{l}\text { Male } \\
(N=50)\end{array}$} & \multicolumn{2}{|c|}{$\begin{array}{l}\text { Total } \\
(N=100)\end{array}$} \\
\hline & Mean & $\pm \mathrm{SD}$ & Mean & $\pm \mathrm{SD}$ & Mean & \pm SD \\
\hline Age (years) & 22.34 & 7.13 & 36.3 & 12.39 & 29.89 & 13.55 \\
\hline Height (cm) & 161.2 & 5.21 & 174.7 & 7.20 & 168 & 9.208 \\
\hline Weight (kg) & 65.7 & 12.43 & 85.5 & 22.03 & 75.6 & 20.39 \\
\hline BMI $\left(\mathrm{kg} / \mathrm{m}^{2}\right)$ & 25.19 & 4.25 & 27.971 & 6.71 & 26.58 & 5.763 \\
\hline
\end{tabular}

Abbreviations: BMI; body mass index; SD, standard deviation.

Table 2 The morphometric measurements of umbilicus position in 100 cases according to the sex

\begin{tabular}{|c|c|c|c|c|c|c|c|}
\hline \multirow[t]{2}{*}{ Measurements } & \multicolumn{2}{|c|}{ Female } & \multicolumn{2}{|l|}{ Male } & \multirow[t]{2}{*}{$p$ value } & \multicolumn{2}{|l|}{ Total } \\
\hline & Mean & \pm SD & Mean & \pm SD & & Mean & $\pm S D$ \\
\hline WC & 93.74 & 21.16 & 92.78 & 13.47 & 0.941 & 93.26 & 17.66 \\
\hline $\mathrm{Xu}$ & 17.22 & 2.99 & 18.84 & 3.31 & 0.316 & 18.03 & 3.25 \\
\hline Up & 16.56 & 3.69 & 16.76 & 2.18 & 0.892 & 17.66 & 3.15 \\
\hline$X p$ & 31.14 & 4.39 & 33.28 & 4.66 & 0.123 & 32.21 & 4.64 \\
\hline X-ASISr & 21.76 & 3.76 & 30.14 & 4.011 & 0.574 & 25.95 & 5.72 \\
\hline X-ASISI & 21.42 & 4.12 & 30.26 & 4.05 & 0.380 & 25.84 & 6.02 \\
\hline Xu/Up & 1.04 & 0.18 & 1.14 & 0.21 & 0.20 & 1.0417 & 0.21 \\
\hline $\mathrm{Xu} / \mathrm{Xp}$ & 55.46 & 0.66 & 57.32 & 1.12 & 0.06 & 56.39 & 0.92 \\
\hline Xp/Up & 1.72 & 0.27 & 2.00 & 0.19 & 0.705 & 1.85 & 0.31 \\
\hline Inter-ASIS & 29.16 & 5.242 & 26.9 & 3.75 & 0.069 & 28.3 & 4.68 \\
\hline Xp/inter ASIS & 1.09 & 0.20 & 1.25 & 0.18 & 0.95 & 1.17 & 0.21 \\
\hline U-ASIS & 13.72 & 3.91 & 14.65 & 4.37 & 0.06 & 14.18 & 4.15 \\
\hline U- inter ASIS & 9.44 & 1.45 & 9.07 & 2.17 & 0.654 & 9.25 & 1.84 \\
\hline U-i-hy & 9.50 & 1.64 & 10.31 & 2.58 & 0.783 & 9.91 & 2.19 \\
\hline U-ASIS/inter-ASIS & 48.50 & 0.16 & 54.40 & 0.14 & 0.07 & 51.40 & 0.15 \\
\hline
\end{tabular}

Abbreviation: ASIS, anterior superior iliac spine.

Table 3 Ratios of distances

\begin{tabular}{|l|l|l|}
\hline Ratio & Female & Male \\
\hline Xu/Up & $1.03: 1$ & $1.12: 1$ \\
\hline U-ASIS/ASIA-ASIS & $0.5: 1$ & $0.5: 1$ \\
\hline
\end{tabular}

ASIS right and ASIS left are $25.95 \pm 5.718 \mathrm{~cm}$ and $25.84 \pm$ $6.019 \mathrm{~cm}$, respectively. There were no significant differences between male and female.

Measurements in relation to pubic symphysis: distance from pubic symphysis to umbilicus is $17.66 \pm 3.146 \mathrm{~cm}$; there is no significant differences between male and female.

Measurements in relation to ASIS: distance of umbilicus to ASIS is $14.18 \pm 4.150 \mathrm{~cm}$, while distance of umbilicus to interspinous line is $9.25 \pm 1.844 \mathrm{~cm}$, with no significant differences between male and female. Measurements in relation to inter-anterior hypochondrium line: distance from umbilicus to inter-anterior hypochondrium line is $9.905 \pm$ $2.187 \mathrm{~cm}$, and there is no significant difference between male and female (-Table 2).

\section{Discussion}

In our society, the presence of the umbilicus is a sign of normality, and it reinforce the self-image. The objective of our study is to give guidelines for positioning of umbilicus during abdominoplasty, depending on the morphometric measurements to secure acceptable cosmetic result and patients' satisfaction after surgery.

Parnia et al ${ }^{16}$ performed his study on 65 Iranian adult girls and the mean Xp was $32.26 \pm 2.23 \mathrm{~cm}$ and mean Xu was $17.11 \pm$ $1.64 \mathrm{~cm}$, both of which are close to our results $(32.21 \pm$ 4.636 and $18.03 \pm 3.266$, respectively), while the ratio $\mathrm{Xu} /$ Xp was $53.06 \pm 3.9 \%$, which is lower than our result (56.39 \pm $0.92 \%$ ), and the formula used to demonstrate the anatomical position of umbilicus was: "Xu $=-0.98+0.91 \mathrm{Xp}-0.07 \mathrm{H}$ " $(\mathrm{Xu}=$ distance between umbilicus and xiphisternum, $\mathrm{Xp}=$ distance between pubic symphysis and xiphisternum and " $\mathrm{H}$ " is the height). When applying this formula to our people, the calculation was 16.07 , which did not match with our results.

In females, we found the ratio of distance between xiphisternum and umbilicus and the distance between umbilicus and pubic symphysis is $1.03: 1$, while the ratio of distance between umbilicus and ASIS and the distance between both iliac spines is 0.5:1(see - Table 3); both measurements were lesser than what was observed by Abhyankar et al. ${ }^{17}$

They utilized ratios of $1.6: 1$ and $0.6: 1$, respectively, to mark the new umbilical position by suggesting drawing two 
Table 4 Comparison of our results with others

\begin{tabular}{|l|l|l|l|}
\hline Study & Source & Gender of sample & Position of neoumbilicus (X-U cm) \\
\hline Parnia et al ${ }^{16}$ & Iran & Female & 16.07 \\
\hline Bilgen et al ${ }^{18}$ & Turkey & $\begin{array}{l}\text { Female } \\
\text { Male }\end{array}$ & 11.3 \\
& & Female mainly & 12.4 \\
\hline Rodriguez-Feliz et al $^{19}$ & USA & Female (middle age) & 16.05 \\
\hline${\text { Dudukovic et a }{ }^{20}}$ & Turkey & Female & 16.7 \\
\hline Abhyankar et al ${ }^{17}$ & INDIA & Female & 25.69 \\
\hline Our study & IRAQ & Male & 17.22 \\
& & 18.84 \\
\hline
\end{tabular}

circles at the centers of which are the ASIS, with a radius $0.6 \times$ inter-ASIS distance, and the location of the umbilicus being the intersection upper point in light of 1.6:1 ratio.

The Turkish study by Bilgen et al. ${ }^{18}$ reported that the mean distance of the measurements of $\mathrm{Xu}$ and $\mathrm{Xp}$ in females were $19.3 \mathrm{~cm}$ and $33.4 \mathrm{~cm}$ and in males were $22.4 \mathrm{~cm}$ and $37.0 \mathrm{~cm}$, which are higher than our results, $17.22 \mathrm{~cm}$, $31.14 \mathrm{~cm}, 18.84 \mathrm{~cm}$ and $33.28 \mathrm{~cm}$, respectively. We found the mean Up distance $16.56 \mathrm{~cm}$ in females and $16.67 \mathrm{~cm}$ in males were both higher than that in the Turkish study (14.5 $\mathrm{cm}$ and $14.7 \mathrm{~cm}$, respectively) and also did not match the figure concluded by Rodriguez-Feliz et al, ${ }^{19}$ who stated that on average the distance was $15.0 \mathrm{~cm}$.

We found that the distance between xiphoid and umbilicus $(\mathrm{Xu})$ and between umbilicus and pubic symphysis (Up) were $17.2 \mathrm{~cm}$ and $16.56 \mathrm{~cm}$, respectively, which is roughly near what Dudukovic et $\mathrm{al}^{20}$ had measured in the middle-aged women group; $16.7 \mathrm{~cm}$ for both $\mathrm{Xu}$ and Up, and they predicted the umbilical position in female by using the distance from inter anterior hypochondrium line "U-i-hy" with the help of the following equation: "U-i- hy = $\mathrm{BM} \times-0.1116+\mathrm{WC} \times 0.0706-4.5510 "$ while in male, based on the distance of umbilicus to interspinous: " $\mathrm{U}-\mathrm{i}-\mathrm{is}=$ age $\times$ $0.2033+\mathrm{BM} \times 0.6445+\mathrm{BH} \times-0.5692+\mathrm{BMI} \times-2.2802+\mathrm{WC} \times$ $-0.0911+101.9408$ " (U-i-is mean distance from umbilicus to interspinous line; BM: body mass; BH: body height). But if we apply these equations, the supposed distance between umbilicus and inter-anterior hypochondrium line in females well be $0.74 \mathrm{~cm}$ only, while it is $9.5 \mathrm{~cm}$, and in males, the supposed distance between umbilicus and interspinous line well be $27.42 \mathrm{~cm}$, while it is $9.04 \mathrm{~cm}$ in our people, so both equations cannot be applied to our people.

In this study, the anthropometric measurements related to umbilicus in females were: waist circumference $93.74 \pm$ $21.61 \mathrm{~cm}$, xiphoid to pubis $31.14 \pm 4.39 \mathrm{~cm}$, xiphoid to umbilicus $17.22 \pm 2.99 \mathrm{~cm}$ and umbilicus to pubis $16.56 \pm$ $3.69 \mathrm{~cm}$, while the corresponding measurements in males were $92.78 \pm 13.47 \mathrm{~cm}, 33.28 \pm 4.66 \mathrm{~cm}, 18.84 \pm 3.31 \mathrm{~cm}$, and $16.67 \pm 2.18 \mathrm{~cm}$.

In addition, we found the umbilicus as a midline structure, central, or within $0.6 \mathrm{~cm}$ from the center in females, while in males, it is more inferiorly placed and deviated from the center.

The variation of morphometric measurements, regarding the umbilicus, in different studies as summarized in
- Table 4, can be attributed to geographical, ethnic, genetic and BMI factors in addition to various methodology applied.

Our study represents a trial to spot the proper umbilical position by providing full anthropometric measurements and to get patients' satisfaction postabdominoplasty, yielding a good outcome and protecting surgeons from claims.

The limitation of our study is that all volunteers were of Arab ethnicity in Basra, and Iraq is a multiethnic country, so a multicenter study is recommended to provide a national guideline.

\section{Conclusion}

There are different ways to measure the proper site of the neoumbilicus, and the surgeon should depend on the local anthropometric measurements to have the most convenient place. We found the umbilicus as a midline structure, central, or within $0.6 \mathrm{~cm}$ from the center in females, while in males, it is more inferior.

\section{Conflicts of Interest}

None declared.

\section{References}

1 Fahmy M, Umbilicus and Umbilical Cord. Cham, Switzerland: Springer International Publishing AG; 2018:105-108

2 Snell R, Clinical Anatomy by Regions. 9th ed. Walters Kluwer, Lippincott Williams and Wilkins; 2012151

3 Hegazy AA. Anatomy and embryology of umbilicus in newborns: a review and clinical correlations. Front Med 2016; 10(3):271-277

4 Fawkner-Corbett D, Nicholson JA, Bullen T. Cross P, Bailey $\mathrm{D}$, Scott $\mathrm{MH}$. Anatomical variation in the position of the umbilicus and the implications for laparoscopic surgery. Int J Surg 2010;8(7):540-578

5 Du-Plessis DJ, A Synopsis of Surgical Anatomy. 11th ed. Bristol: John Wright and Son Ltd; 1975

6 Smith T, Pinnock C, Lin T, Jones R. Fundamentals of Anesthesia. 3rd ed. Cambridge: Cambridge University Press; 2009:77-104

7 Farquharson M, Hollingshead J, Moran, B. Farquharson's Textbook of Operative General Surgery (9th edn). London, United Kingdom: Hodder Arnold; 200W5:201

8 Williams AM, Brain JL. The normal position of the umbilicus in the newborn: an aid to improving the cosmetic result in exomphalos major. J Pediatr Surg 2001;36(7):1045-1046

9 Davari H, Nazem M. The normal position of umbilicus in the newborn: an aid to improve cosmetic result in exomphalos major. J Res Med Sci 2004;1:34-38 
10 Shaw WW, Aston SJ, Zide BM, Reconstruction of the trunk. In: Joseph GM, ed. Plastic Surgery, Volume 6. Philadelphia: WB Saunders; 1990:3675-3796

11 Marconi F. Reconstruction of the umbilicus: a simple technique. Plast Reconstr Surg 1995;95(6):1115-1117

12 Harii K, Torii S, Nakajima T, Aoyama H, Matsuo K. Plastic, Reconstructive and Aesthetic Surgery. Amsterdam: Kugler Publications BV; 1995:149

13 Hunstad JP, Repta R, The umbilicus in body contouring. In: Atlas of Abdominoplasty. Philadelphia: Elsevier Inc; 2009:141-156

14 Schwartz SI, Brunicardi FC, eds. Schwartz's Principles of Surgery. New York: McGraw-Hill Medical; 2010

15 Joseph WJ, Sinno S, Brownstone ND, Mirrer J, Thanik VD. Creating the perfect umbilicus: A systematic review of recent literature. Aesthetic Plast Surg 2016;40(3):372-379

16 Parnia R, Ghorbani L, Sepehrvand N, Hatami S, BazarganHejazi S. Determining anatomical position of the umbilicus in Iranian girls, and providing quantitative indices and formula to determine neo-umbilicus during abdominoplasty. Indian J Plast Surg 2012;45(1):94-96

17 Abhyankar SV, Rajguru AG, Patil PA. Anatomical localization of the umbilicus: an Indian study. Plast Reconstr Surg 2006; 117(4):1153-1157

18 Bilgen F, Duman Y, Ural A, Bekerecioglu M. Determining anatomical position of the umbilicus in Turkish population. Indian J Surg 2020

19 Rodriguez-Feliz JR, Makhijani S, Przybyla A, Hill D, Chao J. Intraoperative assessment of the umbilicopubic distance: a reliable anatomic landmark for transposition of the umbilicus. Aesthetic Plast Surg 2012;36(1):8-17

20 Duduković M, Kisić H, Baez ML, et al. Anatomical prediction for surgical positioning of the umbilicus in a white population. Ann Plast Surg 2015;75(2):135-139 